\title{
TR.ANSI.ATOR'S PREFACE
}

Kaufmann's Lehrbuch has seldom been far from the reach of the translator from the time he first began his work as a professional pathologist, and sections of it had already been translated for general use in this laboratory before the seventh and eighth editions appeared, therefore it was only natural that he should undertake the translation of the entire work into English. The task has been considerable, but the reward has been commensurate, not alone in clarifying and systematizing the knowledge gained in the translator's active pathological practice, but also in the pleasure of entering closely with the author into discussions of his favorite subject.

As a result of twelve years teaching experience; of intimate contact with many young and active hospital interns, also of close association with clinicians and patients who have presented their problems for solution, the translator has acquired a firm idea of how pathology should be taught to students of medicine so as to make them fit, when physicians, to take proper care of the sick. He believes that the most important thing a teacher of pathology can do is to help prepare students to become good doctors. Hence in the few paragraphs which the translator has felt called upon to add to the work, he has endeavored to emphasize the relationship of pathology to the sick and how the knowledge of that relationship can help the physician.

The translator has the fullest sympathy with the viewpoint that has been stressed so much in recent years, namely, that of pathological physiology, consequently the reader will find much upon this subject in the text. It is well to remember, however, before we can say, or even speculate on how a condition occurs, and what its dynamics are, that it is necessary to know what it is, and this we shall learn from Kaufmann's pathological anatomy. Of what avail is a discussion of the pathological physiology of atrophic cirrhosis of the liver, when, in reality, the liver about which we are speaking shows, not atrophic cirrhosis, but biliary cirrhosis, due to ascending cholangitis which is secondary to cholelithiasis?

Pathological anatomy is an art as well as a science, in fact, about $80 \%$ art and $20 \%$ science. It takes time and experience to acquire the necessary familiarity and knowledge to assign or designate lesions properly. This, the time devoted to pathological anatomy pure and simple, cannot, in fact, dare not, be slighted if pathological physiology and subsequent clinical medicine are to be mastered. 
Then, there is the problem of tumor diagnosis: If it is important to have clinical insight into other pathological subjects, it is doubly important in this. It is not to confuse the medical student in his undergraduate studies, nor to deny the broad general principles of tumor diagnosis which have been taught to him, but merely to emplant a fact which should be implanted early, namely, that a correct diagnosis of many tumors cannot be made unless complete clinical data are submitted and considered in connection with the gross and microscopic pictures. And even then, we cannot always determine what the tumor is, but have to wait until time has elapsed and we have observed the sequelae in the patient. In other words, histological malignancy is not always biological malignancy, although, usually, it is; a section alone is not always sufficient to tell the whole story.

Naturally, many of those pathological conditions with which the translator has become especially familiar, such as diseases of the abdominal and thoracic viscera, could have been discussed in greater detail in the translation and his own point of view, or the point of view developed by the staff of The Lankenau Hospital as a group, could have been more emphasized. In most instances, however, it will be found that the author has at least mentioned them, so that, while the translator probably could have enlarged upon certain features, or thoughts, he feels that enough (little though it be) has been given to arouse the interest of the diligent reader.

The literature given by Kaufmann will be found in full, as in the German text. Some few references added by the translator will be found appropriately placed in the text itself.

Some liberties have been taken with subheadings and divisions, but in the main the original has been faithfully followed.

The drawings (considerably over one hundred) for the additional or supplementary pictures, which the translator thought would be materially helpful to the reader, were made by our staff artist, Mrs. W. B. Keighton (Eleanor M. Paxson) to whom he is deeply indebted for them. They are some of many which have accumulated in this laboratory during the last few years. These pictures are indicated by L. H. at the end of the legends.

The translator also has had much help, particularly from his assistant, Dr. C. E. Becker, and from Miss L. Snellbaker. He wishes also to record his thanks to Miss M. T. Shutt for her faithful writing of the manuscript, much from dictation, more by way of mechanical devices.

He also expresses thanks to the publishers for their patience and care throughout the preparation of this edition. 